\title{
Features of Begonia grandis adaptation in contrasting cultivation conditions
}

\author{
Elena Baikova $^{1 *}$, and Tatiana Fershalova ${ }^{1}$ \\ ${ }^{1}$ Central Siberian Botanical Garden of the Siberian Branch of the Russian Academy of Sciences \\ (CSBG SB RAS), 630090 Novosibirsk, Russia
}

\begin{abstract}
The possibilities of adaptation of Begonia grandis Dry., the most cold-resistant representative of the genus, to conditions of the foreststeppe zone of Western Siberia, more severe than in areas of natural growth in China, are studied. The experiment carried out outdoors in spring-summer-autumn period in comparison with a year-round greenhouse cultivation. It was established that the development of plants placed outside the greenhouses accelerates: the flowering time was reduced by 1.5 times and fruiting began two months earlier. The productivity indicators increased such as the number of simultaneously blooming inflorescences, the number of female flowers in separate inflorescence and the number of ripened fruits. The coefficient of vegetative propagation also increased. The number of bulbils was almost 2.5 times more, with significant increase in their size. It was shown that plants of $B$. grandis grown in the open air were adapted to the conditions of the forest-steppe of Western Siberia. By the time of autumn frosts, they are completing flowering, form ripen seeds and bulbils. Thus, reproduction is provided both by seed and vegetative means. However, to undergo the full life cycle of $B$. grandis it is necessary to keep dormant tubers in greenhouse or shelter during the frosty period.
\end{abstract}

\section{Introduction}

The genus Begonia L. is one of the largest ones among angiosperms. Its representatives distributed mainly in tropical regions of the world [1,2]. The main diversity of species is concentrated in the rainforests of Brazil, Southeast Asia with adjacent islands and Central Africa. Most begonias belong to the group of thermophilic plants - megaterms, according to the classification of C. Raunkiaer [3]. The optimum air temperature for them is $+20 \ldots+$ $28{ }^{\circ} \mathrm{C}$ [4]. Only a few species are mesotherms that can tolerate drops in air temperature to negative values. The most cold-resistant of them is Begonia grandis Dry., a representative of the section Diploclinium (Lindl.) A.DC., which includes more than 100 species from Southeast Asia [5]. Its area covers a significant territory of China, from Yunnan in the south to Liaoning in the north, from Tibet in the west to Zhejiang in the east [6], it also includes Taiwan [7]. B. grandis is a polymorphic species. Its northern distribution limits reach $40{ }^{\circ} \mathrm{N}$ and coincide with the northern boundary of the genus

* Corresponding author: elenabaikova@mail.ru 
Begonia range. Heavy precipitation occurs in B. grandis habitat areas during the summer months, and winters are cold and dry. The average air temperature in winter is $-4{ }^{\circ} \mathrm{C}$, the minimum - up to $-20^{\circ} \mathrm{C}$ [8]. In natural habitats, underground tubers of $B$. grandis, covered with leaf litter, can tolerate short-term cooling to $-20^{\circ} \mathrm{C}[6]$.

B. grandis is the most cold-resistant representative of the genus Begonia, so we have chosen it as a model species for studying the possibility of adaptation to a temperate climate, more severe than in areas of natural growth. We have previously studied various aspects of the adaptation of this species. In particular, the effect of accumulation of secondary metabolites on the adaptive capabilities of this species was studied [9-11]. The purpose of the study is to detect the developmental rhythms and biological features of $B$. grandis in contrasting growing conditions in the forest-steppe zone of Western Siberia such as year-round cultivation in a greenhouse and outdoor cultivation in spring-summer-autumn period.

\section{Material and methods}

The studies carried out for three growing seasons (2017-2019) on the base of greenhouses of the Central Siberian Botanical Garden of the Siberian Branch of the Russian Academy of Sciences (CSBG SB RAS, Novosibirsk, Russia). For the experiment, 40 samples of $B$. grandis planted in identical pots. Half of the ones were taken out of the greenhouse into the open air after establishing an average daily air temperature of $+10{ }^{\circ} \mathrm{C}$ (second decade of May) and were brought back after the complete death of the aboveground part (second half of September). Control plants were grown year-round in a greenhouse, where the air temperature did not drop below then $+15^{\circ} \mathrm{C}$.

The climate of Novosibirsk is continental; its essential feature is the rapid heating of air in spring and its intensive cooling in autumn [12]. The average monthly daily air temperature in August is $+16^{\circ} \mathrm{C}$, the minimum $+10{ }^{\circ} \mathrm{C}$. In September the values of these indicators decrease, respectively, to $+10^{\circ} \mathrm{C}$ and $+2{ }^{\circ} \mathrm{C}$. Outdoor begonias from the third decade of August were exposed to short-term exposure to low predawn temperatures. The night air temperature dropped to $+5{ }^{\circ} \mathrm{C}$ in the early September and frosts with a decrease in temperature to $-5^{\circ} \mathrm{C}$ were observed in mid-September. This caused the death of the aerial parts of $B$. grandis plants.

Throughout the growing season, phenological observations were carried out according to the standard method modified for the genus Begonia [13]. All female flowers were pollinated artificially, which contributed to the formation of capsules with full seeds.

\section{Results}

Experimental specimens of B. grandis at the time of transfer from the greenhouse to the open air were in the vegetative phase (moderate growth). By the dates of the beginning of reproductive development, plants placed in the open air did not differ from the control samples remaining in the greenhouse. The flower-budding of all begonias was noted at the end of June, the beginning of flowering - in the first ten days of July, and in early August the plants already bloomed en masse (Fig. 1). However, the duration of mass flowering of specimens outside the greenhouse was small - only about 2 weeks. At the beginning of September, they began to form fruits (capsules) and bulbils, specialized structures for vegetative propagation developing in the axils of leaves $[6,13]$. This is probably due to a decrease in night temperatures to $+8{ }^{\circ} \mathrm{C}$, starting from the third decade of August. Fruiting and the formation of bulbils in the greenhouse occurs much later, in mid- 
November. These bulbils are much smaller $(2-3 \mathrm{~mm})$ than ones formed in the open air (up to $9 \mathrm{~mm})$.

By mid-September the night frosts with a decrease in temperature to $-5{ }^{\circ} \mathrm{C}$ begins. The aerial parts of $B$. grandis outdoors samples dies and the plants became dormant in the form of an underground tuber. In the greenhouse, the maturation of seeds and bulbils continued until early December. Then the plants went into a dormant state with the death of aerial shoots.

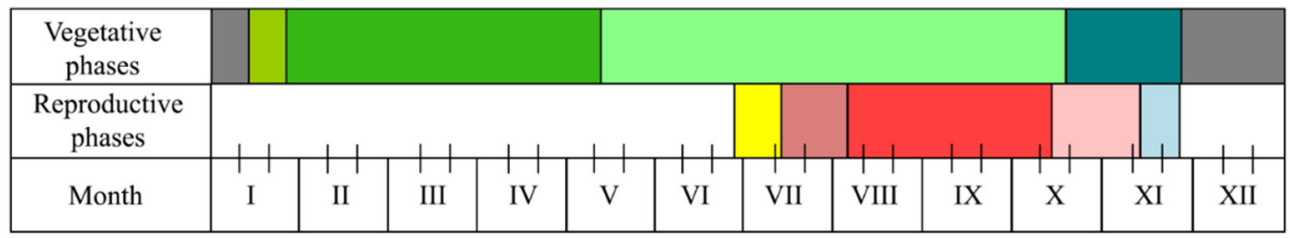

a

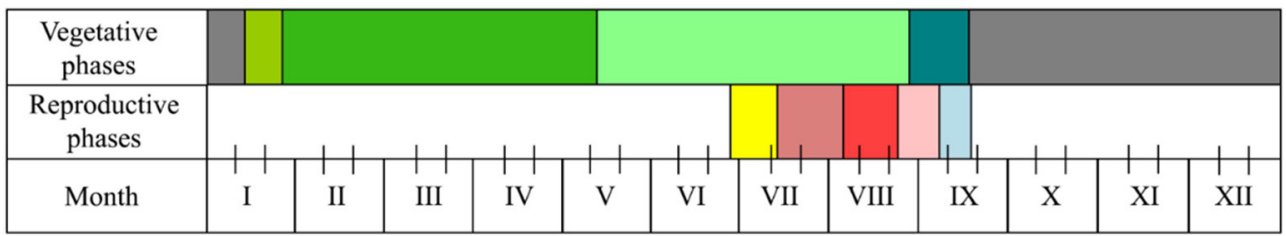

b

\begin{tabular}{|l|l|}
\hline & Beginning of growth \\
\hline & Intensive growth \\
\hline & Moderate growth \\
\hline & Stunted growth \\
\hline & Death of aerial parts \\
\hline
\end{tabular}

\begin{tabular}{|l|l|}
\hline & Flower-budding \\
\hline & Beginning of flowering \\
\hline & Mass flowering \\
\hline & Ending of flowering \\
\hline & Fruiting \\
\hline
\end{tabular}

Fig. 1. Phenological spectra of Begonia grandis: year-round cultivation in the greenhouse (a) and growing outdoors in the spring-summer-autumn period (b).

There were fewer inflorescences per one plant, blooming at the same time in the greenhouse than outdoors - on average, three inflorescences versus four (Table 1). However, the total number of inflorescences during the growing season was significantly greater in the greenhouse than in the open air, since in the latter plants the death of the aerial part occurred much earlier due to night frosts. Formed by this time but not ripened capsules fell off, which also contributed to a decrease in the total seed productivity of plants outside greenhouses.

Table 1. Productivity of Begonia grandis in various cultivation conditions.

\begin{tabular}{|c|c|c|c|c|c|c|}
\hline & \multicolumn{3}{|c|}{ Number per 1 plant, pcs. } & \multicolumn{3}{c|}{ Number per 1 inflorescence, pcs. } \\
\cline { 2 - 7 } & $\begin{array}{c}\text { Inflorescences } \\
\text { at the same time }\end{array}$ & $\begin{array}{c}\text { Inflorescences } \\
\text { per season }\end{array}$ & Bulbils & $\begin{array}{c}\text { Flowers } \\
\text { female }\end{array}$ & $\begin{array}{c}\text { Flowers } \\
\text { male }\end{array}$ & $\begin{array}{c}\text { Matured } \\
\text { capsules }\end{array}$ \\
\hline Greenhouse & $3 \pm 1$ & $12 \pm 2$ & $5 \pm 1$ & $1 \pm 1$ & $10 \pm 1$ & $1 \pm 1$ \\
\hline Outdoor & $4 \pm 1$ & $7 \pm 1$ & $12 \pm 1$ & $4 \pm 1$ & $12 \pm 1$ & $2 \pm 1$ \\
\hline
\end{tabular}


On the contrary, the productivity of a single inflorescence in the open air was higher: the number of female flowers per inflorescence was 4 times greater, and the number of matured capsules was two times more than that of specimens grown in the greenhouse.

The diameter of underground tubers in samples of $B$. grandis grown in the open air was 20-25 $\mathrm{mm}$ by the end of the growing season (mid-September). In greenhouse specimens, at the same time, tubers were smaller - 15-20 $\mathrm{mm}$ in diameter.

\section{Discussion}

A comparative study of phenorhythm, flowering, fruiting and vegetative propagation of $B$. grandis under contrasting cultivation conditions revealed the following features of development and adaptation. Plants in both experience and control have a dormant period in the form of an underground tuber. However, the duration of this period varies significantly. Aerial shoots of $B$. grandis naturally die in the greenhouse only in early December, and in the open air aboveground parts of plants freeze in mid-September when the temperature drops to $-5{ }^{\circ} \mathrm{C}$ at night. The flowering time of $B$. grandis in the greenhouse is 1.5 times, and the mass flowering is 4.5 times longer than outdoors. The flowering of $B$. grandis in the greenhouse is 1.5 times longer than outdoors, and the mass flowering is 4.5 times longer. When the plants were placed outside greenhouses, their development accelerated. Fruiting (forming of the capsules) in the open air began in early September two months earlier than in the greenhouse, although phenological phases of flower-budding and the beginning of flowering were simultaneous under both conditions. Such phenorhythm is similar to ones of $B$. grandis in nature [14].

The total number of inflorescences on plants located in greenhouses was almost 2 times higher than in the open air due to the length of the flowering period. Wherein the flowering intensity increased outdoors - the average number of simultaneously flowering inflorescences was greater. Cultivation of $B$. grandis in the open air caused an increase in the productivity of an individual inflorescence: the number of female flowers per inflorescence increased on average by 4 times, the number of matured capsules - by 2 times. However, the total seed productivity of $B$. grandis in the greenhouse is higher due to prolonged flowering, which allows the formation of a larger number of inflorescences.

The coefficient of vegetative propagation, on the contrary, turned out to be higher in plants in the open air - the number of bulbils was almost 2.5 times greater, with a significant increase in their size. The intensification of the bulbils formation outside greenhouses is obviously associated with hormonal changes in the meristems under the influence of low temperatures. These processes indicate the preparation of plants for an unfavorable season, as well as the increase the size of underground tubers due to the accumulation of plastic substances.

$B$. grandis plants grown in the greenhouse have a distinct dormant period (Decemberearly January), despite favorable temperature conditions. It is known that plant phenorhythms depend both on external factors and on endogenous rhythms caused genotypic organization [15-17]. Our previous studies showed that the onset of dormancy in $B$. grandis plants determined by the endogenous rhythm [13]: growth processes are inhibited and the aerial parts of the shoots die, even under favorable conditions.

The results obtained allow us to conclude that the samples of $B$. grandis were adapted to the conditions of cultivation in the open air during the spring-summer-autumn period. By the time of the onset of autumn frosts, they are completing flowering by forming mature seeds and bulbils - structures for vegetative propagation. Thus, the functions of reproduction and propagation by both seed and vegetative processes are ensured, which 
makes it possidie to enticienuy grow tnese piants in an annual cuiture. nowever, in order to undergo the full life cycle in the conditions of the forest-steppe zone of Western Siberia, which are more severe than those in natural habitats of $B$. grandis, it is necessary to exclude freezing of the dormant tuber in winter. The negative impact of low freezing temperatures can be avoided by growing $B$. grandis indoors. However, lowering the temperature in the greenhouse in the second half of November and December is required to ensure a genetically determined dormant period.

The work was carried out within the framework of the State Assignment of Central Siberian Botanical Garden SB RAS. When preparing the publication, the materials of bioresource scientific collection of CSBG SB RAS «Collections of living plants indoors and outdoors», USU 440534 were used.

\section{References}

1. P.W. Moonlight, W.H. Ardi., L.A. Padilla, et al., Taxon 67, 267-323 (2018)

2. V.L. Averyanov, K.S. Nguyen, T.V. Maisak, H.T. Nguyen, H.Q. Nguyen, Turczaninowia 22, 134-141 (2019)

3. C. Raunkiaer, The life forms of plants and statistical plant geography (The Clarendon Press, Oxford, 1934)

4. K.Y. Guan, J. Li, J. Kuang, D. Tian, The Begonian 66, 90-96 (1999)

5. R.R. Rubite, Asia Life Sciences 21, 363-373 (2012)

6. X. Li, D. Tian, C. Li, K. Liu, X. Li, M. Nakata, Botanical Research 3, 117-139 (2014)

7. K. Nakamura, Y.F. Wang, M.J. Ho, K.F. Chung, C.I. Peng, Taiwania 60, 49-53 (2015)

8. M. Kottek, J. Grieser, C. Beck, B. Rudolf, F. Rubel, Meteorology 15, 259-263 (2006)

9. E.A.Karpova, T.D. Fershalova, Tomsk State University Journal of Biology 33, 140158 (2016)

10. E.A. Karpova, T.D. Fershalova, A.A. Petruk, Journal of Stress Physiology \& Biochemistry 12, 44-56 (2016)

11. E.A. Karpova, A.A. Krasnikov, T.D. Fershalova, E.V. Baikova, A.A. Petruk, Yu.L. Yakimova, Botanica Pacifica 8, 51-61 (2019)

12. I.O. Luchitskaya, N.I. Belaya, S.A. Arbuzov, Climate of Novosibirsk and its changes (Publishing House SB RAS, Novosibirsk, 2014)

13. T.D. Fershalova, E.V. Baikova, Introduction of Begonia in greenhouses and interiors (Academic Publishing House "GEO”, Novosibirsk, 2013)

14. C. Gu, C.I. Peng, N.J. Turland, Begoniaceae, in Flora of China 13 (Science Press, Beijing, and Missouri Botanical Garden Press, St. Louis, 2007)

15. K. Koriba, Gardens Bull. Singapore 17, 11-81 (1958)

16. Yu.A. Dudar, Zh. Obshch. Biol. 54, 229-332 (1993)

17. O.B. Mikhalevskaya, Bulletin of the Main Botanical Garden 188, 119-129 (2004) 